\title{
Media coverage of mental health care in the UK, USA and Australia
}

\section{AIMS AND METHOD}

We aimed to assess the contents and tone of articles on mental health care in the UK print media by comparing them with reporting in the USA and Australia.Two broadsheets from each country were analysed using the Internet for a random 4 months over a 1 -year period. The number of articles, their content and the views expressed in them were identified and compared.

\author{
RESULTS \\ A total of 118 articles on mental \\ health care issues were found. The \\ predominant tone of the articles in \\ all three countries was negative, \\ though there were slightly more \\ positive articles in the USA and \\ Australian media. Positive articles \\ highlighted in the UK media covered \\ mostly medical conferences and \\ research findings.
}

\begin{abstract}
CLINICAL IMPLICATIONS
Efforts to achieve a more positive attitude towards people with mental illnesses in the public, such as anti-stigma campaigns, operate against a background of predominantly negative coverage of mental health care issues in broadsheets. The coverage in the UK may tend to be even less positive than in the USA and Australia. Medical conferences and research findings can, however, be used to promote positive views of mental health care in the media.
\end{abstract}

The coverage of events and views expressed in the media is supposed to both reflect public opinion and influence it. Media coverage of mental health care may impact on policies, and is therefore an important area of research. It has been argued that English broadsheets focus particularly on violence and homicides committed by people with mental illness. This has obvious implications for the stigma of mental illness and is a concern for various stakeholders in mental health care (Searle, 1999).

The media coverage of mental health care issues has repeatedly been the subject of empirical research (e.g. Matas et al, 1986; Barnes \& Earnshaw, 1993; Scott, 1994; Philo, 1997; Finzen et al, 1999; Hoffmann-Richter et al, 1999). The press in the UK has been shown to have an influential role in the public attitude towards mental illness as well as its policies in the UK - at least during the past 10 years (Philo \& Secker, 1994; Hallam, 2002). While most studies have confirmed a negative portrayal of psychiatry in the newspapers (Day \& Page, 1986; Matas et al, 1986), one Irish study has not (O'Connor \& Casey, 2001). The impression, however, that UK media take a more negative stance towards mental health care issues than media in other countries has not been substantiated by empirical research yet. An international comparison might help to establish a more precise picture of the particular role of media in one country and provide information on what challenges anti-stigma campaigns face in different countries (Bjegovic \& Ivezic, 2002).

This study aims to assess the contents and tone of articles on mental health care in UK broadsheets by comparing them with the reporting in the USA and Australia. For 4 months, the number of articles, their content and the views expressed in them were examined.

\section{Method}

The study researched broadsheets in the UK, USA and Australia for 4 random months over a 1-year period using the Internet. Two broadsheet newspapers that represented the highest national circulation possible and that were available on the Internet were selected from each country. In the UK, the newspapers investigated were the Guardian and the Daily Telegraph, representing left- and right-wing political leaning, respectively. In the USA, the broadsheets selected were the Los Angeles Times and the New York Times. In Australia, the papers were the Sydney Morning Herald and the Melbourne Age. The 4 months randomly selected were May, October and December 2001 and April 2002.

In the analysis of the broadsheets, the following information was sought:

1. How many articles on mental health care issues were published within the random four months?

2. How many articles on mental health care/psychiatry were published on the front page as opposed to later sections?

3. What was covered in the papers? Topics covered were divided into five broad groups - forensic issues, psychiatric diagnosis and treatment, general information, psychiatric services and medical reports. The term 'medical report' is sometimes used as a title for a special section in the newspapers that contains information from medical conferences and new research published in journals.

4. What views have been expressed towards people with mental illnesses and mental health care? By assessing the tone of the article, they were classified as positive, neutral or negative. 
Articles were analysed using the Internet as published on a daily basis, using the same rater and comparison language. The papers on mental health care issues were identified, focusing on stories dealing with aims and objectives of mental health care and not with isolated treatment methods. As the use of keywords on the Internet missed out some of the relevant articles, all journals were viewed completely to identify papers fulfilling the inclusion criteria. The articles were coded as positive, negative or neutral towards mental health. Where coding was unclear, another rater would be used to reach a consensus. A random sample of 20 papers was coded blindly by two independent raters, and there was an $80 \%$ agreement with the coding system. A content analysis of the articles was conducted using the above defined and a posteriori formed categories.

\section{Results}

A total of 118 articles related to mental health issues were identified in the six investigated broadsheets over 4 months. The total numbers were: UK 38, USA 39, and Australia 41. Only one article related to mental health care issues was covered on the front page of the Los Angeles Times, and this was about health insurance being proposed to include mental illness. Among the topics covered, forensic issues were more common in the UK (19\% of all total articles) and USA (17.7\% of all total articles) media, but less so in the Australian newspapers (7.6\% of all total articles). Australian media covered more general articles related to mental health issues $(17.7 \%$ of all total articles) than the UK (4.2\%) and USA (11.8\%). In regards to the category of psychiatric diagnosis and treatment, this was similarly low for all three countries: UK $1.6 \%$, USA $0.8 \%$ and Australia $0.8 \%$. There were more articles on medical reports in the UK (6.7\%) and Australia $(7.6 \%)$ than in the USA media $(0.8 \%)$. The final category of psychiatric services had minimal reports in the media: UK 0, USA $1.6 \%$ and Australia 0.8\%.

The predominant tone of the articles in all three countries was negative towards mental illness and mental health care: UK $76.3 \%$ of all articles, USA $66.7 \%$ and Australia $58.5 \%$. There were slightly more positive articles regarding mental health published in the media in USA and Australia (28.2\% and $26.8 \%$, respectively) compared with the UK (15.7\%). The positive: negative ratio, leaving the neutrally-toned articles aside, in the UK media was $6 / 29$ (i.e. 0.21 ) v. $22 / 53$ (0.42) in the USA and Australia. Hence, the ratio is twice as high in the USA and Australia as compared with the UK media. Thus, relatively more negative articles were published in the UK, although this difference in the 4 random months failed to reach statistical significance in a $\chi^{2}$ test. The positive articles in the Australian media were related to Government's pledges to increase funding for psychiatry and other specialised areas, such as for the treatment of post-natal depression. In the USA media, positive tones were predominantly related to the Government's attempt to negotiate medical health insurance to cover mental health problems as well as reports on the community mental health services reducing hospitalisation of patients. The UK media's few positive articles were on recent findings in medical reports and conferences, which included the discovery of the 'trigger for Alzheimer's disease' and the lowering of suicide rates from overdoses.

The subject of articles with negative tones varied between the countries to some extent. The UK and USA papers reported similar articles on forensic issues, such as suicide, homicide and neglect. There may have been a slightly higher rate of negative reporting in the USA media than normal as there were four articles related to the 11 September terrorist attacks. In general, the other articles were similar in all three countries, with negative views of the psychiatric services, its medications and treatments.

\section{Discussion}

The study addressed an issue, i.e. media coverage of mental health care, that has attracted some research interest in the past and is relevant for various aspects of mental health policies and initiatives to change public perception of mental health, such as anti-stigma campaigns. It utilised the availability of broadsheet publications on the Internet, and demonstrates that coverage in different countries can be compared using a relatively simple content analysis. Such methodology appears feasible and may be used in more comprehensive and systematic research on the subject in the future.

The three countries investigated in this study are geographically distant from one another, but they are all anglophone and arguably share a similar history of psychiatry. A comparison with other European countries might reveal more significant differences, but this would be methodologically more difficult because of the need to compare connotations in different languages (Priebe \& Finzen, 2002).

The number of articles on mental health care was similar for all three countries in the random 4 months. In all countries, topics relating to mental health care hardly featured on the front page of broadsheets. The topics were driven, on the whole, by the political agenda of the day, such as the events of 11 September 2001, the plight of the asylum seekers in Australia and the forthcoming Government election. The media in all three countries appear to report on mental health issues in a 'reactive' manner. The structure of the national health care system determines the content of some articles. While in the USA and Australia, which do not have a National Health Service, there were several articles concerning issues of medical health insurance, this was never mentioned in the UK media.

In general, a negative tone dominates in the broadsheet coverage of mental health care in all three countries. Yet, there appears to be a trend for even more negative coverage in the UK media than in the USA and Australia. One can only speculate on the reasons for this difference, which needs to be replicated in further research. Factors that possibly influence a different and more negative media coverage in the UK may be: the 
tendency to use issues of health care in the political debate when the health care system is a national one with ultimate responsibility of the Government; the poorer funding of mental health care in the UK as compared with the other two countries, resulting in more gaps in the health care system and a more critical attitude of journalists; and a specific and more scandal-oriented reporting tradition of the print media in the UK.

Whatever the national differences in media coverage are, the study underlines the challenge that all efforts to achieve a more positive attitude towards people with mental illness in the public, such as anti-stigma campaigns, face in the industrialised world. All such initiatives operate against a background of predominantly negative coverage of mental health care issues in broadsheets. However, there is also positive coverage, although such articles are in the minority. All newspapers published articles with a positive tone under the category of 'medical reports' and 'general information'. These articles may have increased awareness of mental health, its services and treatment, and were often related to events such as medical conferences and the dissemination of new research findings. One might conclude that conferences and research publications could be utilised more proactively to promote positive views of mental health care and to increase the general public's awareness of psychiatry.

\section{Acknowledgement}

We would like to thank Mr David McWilliams as the second independent rater.

\section{Declaration of interest}

None.

original

papers

\section{References}

BARNES, R. C. \& EARNSHAW, S. (1993) Mental illness in British newspapers (or My Girlfriend is a Rover Metro). Psychiatric Bulletin, 17, 673-674.

BJECOVIC, M. B. \& IVEZIC, S. (2002) Anti-stigma program as the part of therapy intervention. Schizophrenia Research, 53, 263.

DAY, D. M. \& PAGE, S. (1986) Portrayal of mentalillness in Canadian newspapers. Canadian Journal of Psychiatry, 31, 813-817.

FINZEN, A., WICK, F., ALDER, B., et al (1999) Minor tranquillizers in the printed media. Psychiatrische Praxis, 26, 194-198.

HALLAM, A. (2002) Media influences on mental health policy: long term effects of the Clunis and Silcock cases. International Review of Psychiatry, 14 26-33.

HOFFMANN-RICHTER, U., WICK, F., ALDER, B., et al (1999) Neuroleptic drugs in the printed media.

Psychiatrische Praxis, 26, 175-180

MATAS, M. EL-GEUBALY, N., HARPER, D., et al (1986) Mental illness and the media: content analysis of press coverage of mental health topics. Canadian Journal of Psychiatry, 31, 431-433.

O'CONNOR, A. \& CASEY, P. (2001) What it says in the paper: an audit. Irish Journal of Psychiatric Medicine, 18, $68-71$

PHILO, G. (1997) Changing media represenations of mental health Psychiatric Bulletin, 21, 171-172.

— \& SECKER, J. (1994) What the papers say. Community Care, February, 24

PRIEBE, S. \& FINZEN, A. (2002) On the different connotations of social psychiatry. Social Psychiatry and Psychiatric Epidemiology, 37, 47-49.

SCOTT, J. (1994) What the papers say. Psychiatric Bulletin, 18, 489-491.

SEARLE, G. (1999) Stigma 1, Psychiatrists 0. Psychiatric Bulletin, 23 430.

Beatrice Huang Specialist Registrar, Royal Free Hospital, Camden \& Islington Mental HealthTrust, *Stefan Priebe Professor of Social and Community Psychiatry, Unit for Social and Community Psychiatry, Barts and the London School of Medicine, Queen Mary, University of London. Postal address: Academic Unit, Newham Centre for Mental Health, London E13 8SP 